Journal of Animal and Veterinary Advances 11 (5): 649-654, 2012

ISSN: $1680-5593$

(C) Medwell Journals, 2012

\title{
Effects of Fermented Soybean Meal on Performance, Serum Biochemical Parameters and Intestinal Morphology of Laying Hens
}

\author{
${ }^{1,2}$ F.Z. Xu, ${ }^{1,2}$ L.M. Li, ${ }^{1}$ H.J. Liu, ${ }^{2} \mathrm{~K}$. Zhan, ${ }^{2} \mathrm{~K}$. Qian, ${ }^{2} \mathrm{D}$. Wu and ${ }^{1,2}{ }^{2} \mathrm{X}$.L. Ding \\ ${ }^{1}$ College of Animal Science and Technology, Anhui Agricultural University, \\ 230036 Hefei, P.R. China \\ ${ }^{2}$ Anhui Animal Biological Engineering Technology Research Center, 230031 Hefei, P.R. China
}

\begin{abstract}
This experiment was performed to compare the effects of fermented soybean meal (fermented with Bacillus licheniformis D-1, FSBM) and Soybean Meal (SBM) on performance, serum biochemical parameters and intestinal morphology of laying hens. About 288, 29 weeks old laying hens were randomly allocated into 2 dietary treatments, 4 replicate groups of 36 laying hens each from 29-39 weeks of age. One treatment received the basal diet (containing $22.8 \% \mathrm{SBM}$ ) as control and the other treatment received the basal diet in which the SBM was replaced by FSBM at 2.5\%. At the end of feeding trial, 8 layers of each treatment were killed and their serum and small intestine segments of duodenum, jejunum and ileum segments were collected for serum biochemical parameters and intestinal morphology evaluation. Results showed that FSBM improved performance of laying hens. The laying rate was improved by $3.59 \%(\mathrm{p}<0.05)$. Feed/egg ratio was decreased by $4.00 \%(\mathrm{p}<0.05)$. Hens fed FSBM had lower levels of serum urea nitrogen $(\mathrm{p}<0.05)$ and a higher content of serum total phosphorus $(\mathrm{p}<0.05)$. Birds fed FSBM had a higher level of serum IgA and IgG than birds fed entire SBM $(\mathrm{p}<0.05)$. FSBM increased $(\mathrm{p}<0.05)$ villus height and villus height to crypt depth ratio in the duodenum and jejunum compared with whole SBM. There were no effects of FSBM on hen's ileum mucosa morphology. Therefore, it was concluded that FSBM had beneficial effects on performance of laying hens and thus, decrease or overcome the negative effect of SBM on egg-laying hens.
\end{abstract}

Key words: Laying hen, performance, serum parameter, fermented soybean meal, morphology, China

\section{INTRODUCTION}

Soybean Meal (SBM) is an important source of dietary protein. High protein content and widespread availability make soybean meal a good source of protein in animal diets. However, the presence of important Anti-Nutritional Factors (ANFS) such as Trypsin Inhibitor (TI), soya globulins etc., affect the nutritional value of SBM (Jiang et al., 2000; Batal and Parsons, 2003; Fasina et al., 2004). Fermentation has long been used to prepare healthy foods for humans (Kim et al., 1999). Fermented SBM (FSBM) can provide partially digested soy proteins that are utilized better that have trypsin inhibitors removed. Fermentation of SBM can also provide live microorganisms that are beneficial to the gut health of animal (Lee, 1998). Fermentation with Aspergillus oryzae, a fungus widely used in soy food preparation could decrease TI and enhance the content of small-size peptide in soybean and SBM (Hong et al., 2004; Feng et al., 2007a).
FSBM are highly digestible and nutritious to animal. Chah et al. (1975) showed that diets containing soybeans fermented by certain cultures of Aspergillus significantly improved broiler growth and feed utilization. Fermentation of SBM with Aspergillus increased weight gain and reduced phosphorus excretion in chicks (Hirabayashi et al., 1998). Feng et al. (2007a) showed that fermented soybean meal improve the performance of chicks increase the level of IgA, IgM and total phosphorus content and decreased the urea nitrogen content in serum. FSBM also improved the growth performance of piglets, decreased serum IgG and lowered whole blood and spleen lymphocyte proliferative response to ConA and LPS (Liu et al., 2007). Kim et al. (2010) indicated that FSBM by A. oryzae eliminated adverse effects of feeding SBM to newly weaned pigs and improved their efficiency of nutrient utilization for growth.

Considerable interest has recently been shown in the use of fermented feeds to improve pig or broiler performance and influence on bacterial ecology of their

Corresponding Author: Li Lvmu, Department of Animal Science, College of Animal Science and Technology, Anhui Agricultural University, 230036 Hefei, P.R. China 
gastrointestinal tract (Canibe and Jensen, 2003; Jiang et al., 2006; Canibe et al., 2008). However, data on the effect of FSBM on performance in laying hens is scarce. Therefore, this experiment was conducted to evaluate the effects of SBM fermented with Bacillus licheniformis on performance, serum biochemical parameters and intestinal morphology of layer chickens.

\section{MATERIALS AND METHODS}

Preparation of fermented soybean meal: The Bacillus licheniformis D-1 used was obtained from the China Center for Type Culture Collection as CCTCC M2011167. The FSBM was prepared as per the procedure described by Zamora and Veum (1979). Briefly, the soybean meal was purchased from commercial feed plant and soaked in water at the ratio of 1:1 (1 part soybean meal: 1 part water including bacterial culture). The soybean meal was spread on stainless steel pans to a depth of $3.5 \mathrm{~cm}$. The cooled fermented medium was inoculated with Bacillus licheniformis D-1 at 7\% (V/W) and covered with muslin cloth. These cultures were incubated at $39^{\circ} \mathrm{C}$ for $58 \mathrm{~h}$. After incubation, the samples were dried in a hot air oven at $50^{\circ} \mathrm{C}$ for 3 days. The dried samples were ground in a grinding mill and stored until mixed with the diets.

Chemical analysis: All analyses were performed in duplicate. Fermented soybean meal were sampled and analyzed for dry matter by drying at $105^{\circ} \mathrm{C}$ for $5 \mathrm{~h}$, ash by incineration at $550^{\circ} \mathrm{C}$. Protein $(\mathrm{N} \times 6.25)$ was determined according to the method of Kjeldahl. Trypsin inhibitor was measured as described by Kakade et al. (1969). Small peptide was determined according to the method of Lowry et al. (1951).

Birds' husbandry: About 288, 29 weeks old Hy-line laying chickens were randomly allotted to 2 treatments each of which comprised 4 replicates of 36 hens each. The control birds were fed a corn-SBM based diet and the treatment group fed with the control diet in which the FSBM replaced SBM at $2.5 \%$ (Table 1 ). The experiment lasted for 10 weeks. The hens were kept in 3-tier cage and allowed free access to water and experimental diets. Nutrient levels of the diets (Table 1) met or exceeded recommendations. Eggs laid, egg weights and mortality were recorded daily. Daily feed intake, average egg weight, feed egg ratio and hen-day egg production were calculated every week.

Blood sampling: Blood collection was carried out on the experimental hens at the end of the experiment. About 12 hens were selected from every treatment ( 4 hens per
Table 1: Ingredient composition and nutrient content of experimental diets \begin{tabular}{lcc} 
Ingredient (\%) & $\mathrm{SBM}^{\mathrm{a}}$ & $\mathrm{FSBM}^{\mathrm{b}}$ \\
\hline Corn & 62.00 & 62.00
\end{tabular} $\begin{array}{lrr}\text { SBM } & 23.00 & 20.50\end{array}$

$\begin{array}{lrr}\text { FSBM } & 0.00 & 2.50\end{array}$

$\begin{array}{lll}\text { Powder } & 7.00 & 7.00\end{array}$

DL-Methionine $\quad 0.40 \quad 0.40$

L-Lysine $\cdot \mathrm{HCl} \quad 2.60 \quad 2.60$

$\begin{array}{lrr}\text { Premix }^{1} & 5.00 & 5.00\end{array}$

$\begin{array}{lrr}\text { Total } & 100.00 & 100.00\end{array}$

$\begin{array}{lll}\text { Nutritional level } & & \\ \text { Metabolism energy } & \left(\mathrm{MJ} \mathrm{kg}^{-1}\right) & 11.25\end{array}$

$\begin{array}{lrr}\mathrm{CP}(\mathrm{N} \times 6.25) & 16.00 & 16.00\end{array}$

$\mathrm{Ca} \quad 3.50 \quad 3.50$

\begin{tabular}{lll}
$\mathrm{P}$ & 0.65 & 0.65 \\
\hline
\end{tabular}

${ }^{a}$ SBM $=$ Soybean Meal; ${ }^{b}$ FSBM $=$ Fermented Soybeal Meal. ${ }^{1}$ The premix provided the following (per kilogram of diet): $25,581 \mathrm{IU}$ of vitamin A as vitamin $A$ acetate, $4,800 \mathrm{IU}$ of vitamin $\mathrm{D}_{3}, 32.0 \mathrm{IU}$ of vitamin $\mathrm{E}, 3.0 \mathrm{mg}$ of vitamin $\mathrm{K}_{3}$ as menadione sodium bisulfite, $1.7 \mathrm{mg}$ of vitamin $\mathrm{B} 1$ as thiamine hydrochloride, $6.7 \mathrm{mg}$ of riboflavin, $3.9 \mathrm{mg}$ of vitamin $\mathrm{B}_{6}$ as pyridoxine hydrochloride, $16.0 \mu \mathrm{g}$ of vitamin $\mathrm{B}_{12}, 24.0 \mathrm{mg}$ of niacin, $6.4 \mathrm{mg}$ of D-pantothenic acid as calcium pantothenate, $0.8 \mathrm{mg}$ folic acid, $0.8 \mathrm{~g}$ of choline as choline chloride, $19.6 \mathrm{mg}$ of copper as copper oxide, $182 \mathrm{mg}$ of iron as iron sulfate, $386 \mathrm{mg}$ of manganese as manganese oxide, $330 \mathrm{mg}$ of zinc as zinc oxide, $0.66 \mathrm{mg}$ of selenium as sodium selenite, $1.96 \mathrm{mg}$ of iodide as potassium iodide, $0.30 \mathrm{~g}$ of sodium chloride. ${ }^{2}$ Crude protein, calcium and phosphorus were analyzed values. The metabolizable energy and amino acid content were calculated

replicate) randomly. Blood samples were collected from the wing vein of the hens, the samples were centrifuged at $1600 \times \mathrm{g}$ for $15 \mathrm{~min}$ and collected the serum and the resulting serum was stocked at $-20^{\circ} \mathrm{C}$ until used.

Plasma samples were evaluated for: serum Total Protein (TP), Urea Nitrogen (UN), total Phosphate (P), Calcium (Ca), Immunoglobulin A (IgA), Immunoglobulin $\mathrm{M}(\operatorname{IgM})$ and Immunoglobulin $\mathrm{G}$ (IgG).

Sampling of intestinal tissues: At the end of the experiment, 12 hens were selected from every group (4 hens per replicate) randomly and slaughtered for samples after fasting with free to water for $12 \mathrm{~h}$. The following procedures were conducted using the method of Chiang et al. (2010). Segments were removed from the duodenum, jejunum and ileum. The samples were flushed with physiological saline and fixed in $10 \%$ formalin. Three cross-sections of each sample were prepared after staining with hematoxylin and eosin using standard paraffin embedding procedures. Morphological indices were measured using image processing and analysis system (Version 1, Leica Imaging System Ltd., Cambridge, UK).

Measurement of serum immunoglobulin concentrations: The serum IgG, IgM and IgA contents were determined by the Radial Immunodiffusion Technique as described by Sunwoo et al. (1996).

Statistical analyses: Data were subjected to analysis of variance using the GLM procedure of SAS (SAS Institute, 1996) to test for significant differences among least square 
means and SEM. Pen was considered as the experimental unit for the performance data while individual bird was used as the experimental unit for serum parameters and intestinal morphology.

\section{RESULTS AND DISCUSSION}

The chemical composition of fermented soybean meal: The nutritional analysis of the FSBM was shown in Table 2. The crude protein content was increased from 50.3-55.6\%. After fermentation, the concentration of calcium and phosphorus in soybean meal did not change however, the level of small peptide in SBM increased compared with FSBM (1.8 vs. $24.2 \%$ ). Trypsin inhibitors $\mathrm{t}$ was dropped from $20.0-4.28 \mathrm{mg} \mathrm{g}^{-1}$.

The performance of hens: The performance of the hens is shown in Table 3. Compared to the control, FSBM improved performance of laying hens. The laying rate was improved by $3.59 \% \quad(p<0.05)$. Feed egg ratio was decreased by $4.00 \%(p<0.05)$. There were no significant difference of the average egg weight and daily feed intake in two treatments.

Changes of serum biochemistry parameters: Serum biochemistry parameters are shown in Table 4. When compared with the control, hens fed FSBM had higher level of serum $\operatorname{IgA}, \operatorname{IgG}$ and serum total phosphorus

Table 2: Characteristics of fermented soybeal meal during fermentation

\begin{tabular}{lcc}
\hline Diet $^{\mathrm{a}}$ & $\mathrm{SBM}^{\mathrm{b}}$ & $\mathrm{FSBM}^{\mathrm{c}}$ \\
\hline Dry matter (\%) & 93.4 & 88.10 \\
Crude protein $(\%)$ & 50.3 & 55.60 \\
Calcium $\left(\mathrm{g} \mathrm{kg}^{-1}\right)$ & 8.2 & 8.30 \\
Phosphorus $\left(\mathrm{g} \mathrm{kg}^{-1}\right)$ & 8.6 & 8.50 \\
Small peptide $(\%)$ & 1.8 & 24.20 \\
Trypsin inhibitors $\left(\mathrm{mg} \mathrm{g}^{-1}\right)$ & 20.0 & 4.28 \\
\hline
\end{tabular}

${ }^{\mathrm{a}}$ On a dry matter basis; ${ }^{\mathrm{b}} \mathrm{SBM}=$ Soybean Meal; ${ }^{\mathrm{c}} \mathrm{FSBM}=$ Fermented Soybeal Meal

Table 3: Effect of FSBM on performance of laying hens (29-39 weeks of Items

Laying rate $(\%)$

Average egg weight (g)

Daily feed intake (g)

Feed egg ratio

\begin{tabular}{rrr}
$\mathrm{SBM}^{2}$ & $\mathrm{FSBM}^{3}$ & $\mathrm{SEM}^{4}$ \\
$92.57^{\mathrm{a}}$ & $96.30^{b}$ & 0.21 \\
63.29 & 63.09 & 0.61 \\
115.58 & 116.03 & 1.00 \\
$2.01^{\mathrm{a}}$ & $1.95^{\mathrm{b}}$ & 0.01 \\
\hline
\end{tabular}

${ }^{1}$ Values are presented as means. Means within rows with different letters differ significantly $(\mathrm{p}<0.05) ;{ }^{2} \mathrm{SBM}=$ Soybean Meal; ${ }^{3} \mathrm{FSBM}=$ Fermented Soybeal Meal; ${ }^{4} \mathrm{SEM}=$ Standard Error of the Mean $(p<0.05)$ and lower levels of serum urea nitrogen $(p<0.05)$. But the content of serum total protein and serum total calcium did not differ between birds fed whole SBM and FSBM.

Small intestinal morphology: Morphological measurements of the small intestinal mucosa of hens were shown in Table 5. Birds fed FSBM had higher $(\mathrm{p}<0.05)$ villus height in the duodenum and jejunum than birds fed entire SBM. These birds also had a higher $(\mathrm{p}<0.05)$ crypt depth ratio in the duodenum and jejunum as well. However, there were no significant effects of FSBM on hen's ileum mucosa morphology.

This study evaluated FSBM as a vegetable protein source for laying hens. Fermentation changed the nutritional characteristics of SBM (Table 2). Fermentation of SBM by Bacillus licheniformis D-1 increased crude protein concentrations from $50.3-55.6 \%$. The increase in protein may be due in part to the decreased carbohydrate content after fermentation. The loss of dry matter at the expense of fermentable sugars during fermentation with bacteria, fungi or yeast which itself are optimal sources of proteins could be a possible reason for such an increase in crude protein (Rozan et al., 1996). The content of small peptide in FSBM was increased by $22.4 \%$ compared with SBM. Feng et al. (2007a) indicated that the size of soybean peptide were obviously reduced after fermentation. Most of the peptides in FSBM were $<10 \mathrm{kDa}$ whereas most peptides in SBM were between 20 and $250 \mathrm{kDa}$ (Hong et al., 2004). This indicates that the fermentation process removed a substantial portion of the glycinin and $\beta$-conglycinin that causes villus atrophy and crypt hyperplasia in the small intestine which are $>20 \mathrm{kDa}$ (Li et al., 1990; Rickert et al., 2004).

Table 4: Effect of FSBM on serum biochemistry parameters of layer hens

\begin{tabular}{|c|c|c|c|}
\hline Items & $\mathrm{SBM}^{2}$ & $\mathrm{FSBM}^{3}$ & $\mathrm{SEM}^{4}$ \\
\hline $\operatorname{Ig} A\left(g^{-1}\right)$ & $0.19^{a}$ & $0.32^{b}$ & 0.01 \\
\hline $\operatorname{IgM}\left(\mathrm{g} \mathrm{L}^{-1}\right)$ & 0.40 & 0.42 & 0.01 \\
\hline $\operatorname{IgG}\left(\mathrm{g} \mathrm{L}^{-1}\right)$ & $0.21^{\mathrm{a}}$ & $0.34^{b}$ & 0.02 \\
\hline Total protein $\left(\mathrm{g} \mathrm{L}^{-1}\right)$ & 37.81 & 38.53 & 0.43 \\
\hline Urea nitrogen $\left(\mathrm{mmol} \mathrm{L}^{-1}\right)$ & $1.12^{\mathrm{a}}$ & $1.54^{\mathrm{b}}$ & 0.01 \\
\hline $\mathrm{Ca}\left(\mathrm{mmol} \mathrm{L}^{-1}\right)$ & 6.22 & 6.33 & 0.03 \\
\hline$\underline{\mathrm{P}\left(\mathrm{mmol} \mathrm{L}^{-1}\right)}$ & $1.35^{\mathrm{a}}$ & $1.97^{\mathrm{b}}$ & 0.02 \\
\hline
\end{tabular}

Values with different letters in the same row differ significantly $(\mathrm{p}<0.05)$,

${ }^{1}$ Values are mean for twelve hens. Means within rows with different letters differ significantly; ${ }^{2}$ SBM $=$ Soybean Meal; ${ }^{3}$ FSBM $=$ Fermented Soybeal Meal; ${ }^{4}$ SEM $=$ Standard Error of the Mean

Table 5: Effects of Fermented Soybean Meal (FSBM) on the morphology of the intestinal mucosa at different sites in the small intestine of hens ${ }^{1}$

\begin{tabular}{|c|c|c|c|c|c|c|c|c|c|}
\hline \multirow[b]{2}{*}{ Items } & \multicolumn{3}{|c|}{ Villus height $(\mu \mathrm{m})$} & \multicolumn{3}{|c|}{ Crypt depth $(\mu \mathrm{m})$} & \multicolumn{3}{|c|}{ Villus height/crypt depth ratio } \\
\hline & $\mathrm{SBM}^{2}$ & $\mathrm{FSBM}^{3}$ & $\mathrm{SEM}^{4}$ & $\mathrm{SBM}^{2}$ & $\mathrm{FSBM}^{3}$ & $\mathrm{SEM}^{4}$ & $\mathrm{SBM}^{2}$ & $\mathrm{FSBM}^{3}$ & $\mathrm{SEM}^{4}$ \\
\hline Duodenum & $1510.8^{a}$ & $1758.4^{b}$ & 27.02 & 124.7 & 118.7 & 7.32 & $12.1^{\mathrm{a}}$ & $14.8^{b}$ & 0.55 \\
\hline Jejunum & $1212.8^{a}$ & $1463.3^{b}$ & 24.36 & 125.5 & 113.1 & 8.28 & $9.7^{\mathrm{a}}$ & $12.9^{b}$ & 0.43 \\
\hline Ileum & 728.3 & 726.5 & 17.05 & 120.5 & 124.3 & 7.56 & 6.0 & 5.8 & 0.12 \\
\hline
\end{tabular}

${ }^{1}$ Values are mean for twelve hens. Means within rows with different letters differ significantly $\left(\mathrm{p}<0.05\right.$ ). ${ }^{2} \mathrm{SBM}=\mathrm{Soybean} \mathrm{Meal}$, ${ }^{3} \mathrm{FSBM}=\mathrm{Fermented}$ Soybeal Meal; ${ }^{4} \mathrm{SEM}=$ Standard Error of the Mean 
Trypsin inhibitors are well known to reduce protein digestibility and this reduction becomes more pronounced as trypsin inhibitor concentration increases (Yen et al., 1977; Herkelman et al., 1992). Trypsin inhibitor concentration in SBM also can be reduced by fermentation. In the present experiment, the level of trypsin inhibitor in FSBM was decreased from $20.0-4.28 \mathrm{mg} \mathrm{g}^{-1}$. Hong et al. (2004) found that fermentation with Aspergillus oryzae could decrease TI in soybean meal. Feng et al. (2007a) also proved that TI could be eliminated ( 2.63 vs. $0.00 \mathrm{mg} \mathrm{g}^{-1}$ ) effectively by fermentation.

In current study, the laying rate was improved by $3.59 \%$ and feed egg ratio was decreased by $4.00 \%$ $(\mathrm{p}<0.05)$. The results showed that FSBM improved the performance of laying hens (Table 3). Chah et al. (1975) suggested that the growth promoting activity of the fermented soybeans was largely. Fermented soybeans are highly digestible and nutritious, contributing important nutrients including calcium and vitamins $\mathrm{A}$ and $\mathrm{B}$ as well as having functional properties (Lee, 1998; Kim et al., 1999). Kiers et al. (2003) showed that when piglets were fed fermented soybeans, feed intake, average daily weight gain and feed efficiency were improved significantly. Similarly, research on broiders showed that FSBM significantly increased the average daily gain $(p<0.05)$, average daily feed intake $(\mathrm{p}<0.05)$ in both periods and improved the feed conversion efficiency $(\mathrm{p}<0.05)$ in the growing period (Feng et al., 2007a).

The level of serum IgA and IgG may be associated with the increase of the small size peptides in fermented soybean meal. Fermentation affected the characteristics of proteins in soybean meal. In this experiment, small peptides content was increased from $1.8-24.2 \%$ after fermentation. Wang et al. (2003) found that adding $3 \mathrm{~g}$ small peptides/kg in basal diets fed to piglets increased the concentration of immunoglobulin. Feng et al. (2007a) indicated that FSBM dramatically increased the IgM and IgA content in serum of broiders $(\mathrm{p}<0.05)$. However, it is interesting that the level IgM in serum had no significant change in the study.

In this experiment, a higher content of serum total phosphorus in laying hens fed FSBM compared to the control was observed. Although, the total phosphorus content in FSBM remained the same as that of SBM, microbial phytases can be used to reduce phytic acid content in soybean as a result, the bioavailability of phosphorus were improved. Soybean meal fermentation with A. usamii almost completely degraded phytate phosphorus into inorganic phosphorus (Ilyas et al., 1995) and then improved phosphorus bioavailability in chicks (Hirabayashi et al., 1998; Matsui et al., 1996). In addition, hens fed FSBM had lower levels of serum urea nitrogen. Chah et al. (1975) have found that broilers fed fermented soybeans utilized dietary nitrogen more efficiently than broilers fed SBM. Feng et al. (2007a) showed that broiders fed FSBM urea nitrogen content of serum was reduced $(p<0.01)$ dramatically than broilers fed SBM.

The villus height to crypt depth ratio is a very useful measure to estimate the absorption capacity of the small intestine (Chiang et al., 2010). In the study increased villus height and increased villus height to crypt depth ratio in the duodenum and jejunum were observed in egg-laying hens supplemented with FSBM compared with SBM (Table 5). Maximum digestion and absorption is believed to occur as the villus height to crypt depth ratio increases in weaned pigs (Pluske et al., 1996). Changes in the intestinal morphology such as reduced villus height may also indicate the presence of toxins (Xu et al., 2003). Previous studies also showed that anti-nutritional factors in SBM such as TI and soybean globulins have an adverse effect on the morphology and function of digestive tract in animals (Dunsford et al., 1989; Batal and Parsons, 2003). Feng et al. (2007b) showed that intestinal morphology of broilers fed FSBM were improved compared with SBM in the starter phase. So, the increased villus height and villus height to crypt depth ratio might be associated with a lower level of TI (Table 2) and the degradation of large size protein in SBM after fermentation. The increased villus height to crypt depth ratio produced an intestinal structure more oriented to absorption. Thus, with FSBM, the intestinal structure of the duodenum and jejunum is more favorable for the bird.

\section{CONCLUSION}

The results of the current experiment indicated that fermentation could improve the characteristics of soybean meal and fermented soybean meal could improve the performance of layer hens increase the level of IgA, IgG and total phosphorus content and decreased the urea nitrogen content in serum, enhance villus height and increased villus height to crypt depth ratio in the duodenum and jejunum. Further research is required to better define the mechanisms of effect of the nutrients in FSBM on immune function in layer hens.

\section{ACKNOWLEDGEMENTS}

This study was supported by grants from National Scientific and Technical personnel services company action projects (award number 2009GJC 30021 ) and Anhui Agriculture Science and Technology Transformation Fund Programs (award number 09150306006). 


\section{REFERENCES}

Batal, A.B. and C.M. Parsons, 2003. Utilization of different soy products as affected by age in chicks. Poult. Sci., 82: 454-462.

Canibe, N. and B.B. Jensen, 2003. Fermented and nonfermented liquid feed to growing pigs: effect on aspects of gastrointestinal ecology and growth performance. J. Anim. Sci., 81: 2019-2031.

Canibe, N., H. Miettinen and B.B. Jensen, 2008. Effect of adding Lactobacillus plantarum or a formic acid containing product to fermented liquid feed on gastrointestinal ecology and growth performance of piglets. Livest. Sci., 114: 251-262.

Chah, C.C., C.W. Carlson, G. Semeniuk, I.S. Palmer and C.W. Hesseltine, 1975. Growth promoting effects of fermented soyabeans for broilers. Poult. Sci., 54: 600-609.

Chiang, G., W.Q. Lu, X. S. Piao, J.K. Hu, L.M. Gongand P.A. Thacker, 2010. Effects of feeding solid-state fermented rapeseed meal on performance, nutrient digestibility, intestinal ecology and intestinal morphology of broiler chickens. Asian-Aust. J. Anim. Sci., 23: 263-271.

Dunsford, B.R., D.A. Knabe and W.E. Haensly, 1989. Effect of dietary soybean meal on the microscopic anatomy of the small intestine in the early-weaned pig. J. Anim. Sci., 67: 1855-1863.

Fasina, Y.O., J.D. Garlich, H.L. Classen, P.R. Ferket and G.B. Havenstein et al., 2004. Response of turkey poults to soybean lectin levels typically encountered in commercial diets. 1. Effect on growth and nutrient digestibility. Poult. Sci., 83: 1559-1571.

Feng, J., X. Liu, Z.R. Xu, Y.Y. Liu and Y.P. Lu, 2007a. Effects of Aspergillus oryzae 3.042 fermented soybean meal on growth performance and plasma biochemical parameters in broilers. Anim. Feed Sci. Technol., 134: 235-242.

Feng, J., X. Liu, Z.R. Xu, Y.Z. Wang and J.X. Liu, $2007 \mathrm{~b}$. Effects of fermented soybean meal on digestive enzyme activities and intestinal morphology in broilers. Poult. Sci., 86: 1149-1154.

Herkelman, K.L., G.L. Cromwell, T.S. Stahly, T.W. Pfeiffer and D.A. Knabe, 1992. Apparent digestibility of amino acids in raw and heated conventional and lowtrypsin-inhibitor soybeans for pigs. J. Anim. Sci., 70: $818-826$

Hirabayashi, M., T. Matsui, H. Yano and T. Nakajima, 1998. Fermentation of soybean meal with Aspergillus usamii reduces phosphorus excretion in chicks. Poult. Sci., 77: 552-556.
Hong, K.J., C.H. Lee and S.W. Kim, 2004. Aspergillus oryzae GB-107 Fermentation improves nutritional quality of food soybeans and feed soybean meals. J. Med. Food, 7: 430-435.

Ilyas, A., M. Hirabayashi, T. Matsui, H. Yano, T. Kikushima, M. Takebe and K. Hayakawa, 1995. The note on the removal of phytic acid in soybean meal using Aspergillus usamii. Asian Aust. J. Anim. Sci., 8: $135-138$.

Jiang, H.Q., L.M. Gong, Y.X. Ma, Y.H. He, D.F. Li and H.X. Zhai, 2006. Effect of stachyose supplementation on growth performance, nutrient digestibility and caecal fermentation characteristics in broilers. Br. Poult. Sci., 47: 516-522.

Jiang, R., X. Chang, B. Stoll, K.J. Ellis, R.J. Shypailo, E. Weaver, J. Campbell and D.G. Burrin, 2000. Dietary plasma protein is used more efficiently than extruded soy protein for lean tissue growth in early-weaned pigs. J. Nutr., 130: 2016-2019.

Kakade, M.L., N. Simons and I.E. Liener, 1969. An evaluation of natural vs. synthetic substrates for measuring the antitryptic activity of soybean samples. Cereal Chem., 46: 518-526.

Kiers, J., J. Meijer, M. Nout, F. Rombouts, M. Nabuurs and J. Van Der Meulen, 2003. Effect of fermented soya beans on diarrhoea and feed efficiency in weaned piglets. J. Applied Microbiol., 95: 545-552.

Kim, N., J.L. Yang and Y.S. Song, 1999. Physiological functions of chongkukjang. Food Ind. Nutr., 4: 40-46.

Kim, S.W., E. van Heugten, F. Ji, C.H. Lee and R.D. Mateo, 2010. Fermented soybean meal as a vegetable protein source for nursery pigs: I. Effects on growth performance of nursery pigs. J. Anim. Sci., 88: $214-224$.

Lee, H.J., 1998. Health functional peptides from soybean foods. Korea Soybean Digest., 15: 16-22.

Li, D.F., J.L. Nelssen, P.G. Reddy, F. Blecha and J.D. Hancock et al., 1990. Transient hypersensitivity to soybean meal in the early-weaned pig. J. Anim. Sci., 68: 1790-1799.

Liu, X., J. Feng, Z. Xu, Y. Lu and Y. Liu, 2007. The effects of fermented soybean meal on growth performance and immune characteristics in weaned piglets. Turk. J. Vet. Anim. Sci., 31: 341-345.

Lowry, O.H., N.J. Rosebrough, A.L. Farr and R.J. Randall, 1951. Protein measurement with the folin phenol reagent. J. Biol. Chem., 193: 265-275.

Matsui, T., M. Hirabayashi, Y. Iwama, T. Nakajima, F. Yano and H. Yano, 1996. Fermentation of soya-bean meal with Aspergillus usamii improves phosphorus availability in chicks. Anim. Feed Sci. Technol., 60: 131-136. 
Pluske, J.R., M.J. Thompson, C.S. Atwood, P.H. Bird and I.H. Williams et al., 1996. Maintenance of villus height and crypt depth and enhancement of disaccharide digestion and monosaccharide absorption, in piglets fed on cows' whole milk after weaning. Br. J. Nutr., 76: 409-422.

Rickert, D.A., L.A. Johnson and P.A. Murphy, 2004. Improved fractionation of glycinin and $\beta$-conglycinin and partitioning of phytochemicals. J. Agric. Food Chem., 52: 1726-1734.

Rozan, P., C. Villaume, M.H. Bau, A. Schwertz, J.P. Nicolas and I. Mejean, 1996. Detoxification of rapeseed meal by Rhizopus oligosorus sp. T3: A first step towards rapeseed protein concentrate. Ind. J. Food Sci. Technol., 31: 85-90.

SAS Institute, 1996. SAS User's Guide: Statistics. Version 7.0, SAS Inst. Inc., Cary, NC., USA.

Sunwoo, H.H., T. Nakano, W.T. Dixon and J.S. Sim, 1996. Immune response in chicken against lipopolysacharide of Escherichia coli and Salmonella typhimurium. Poult. Sci., 75: 342-345.
Wang, T., Y.M. Fu, J.L. Lv, H.S. Jiang, Y.P. Li, C.Y. Chen and C.M. Zuo, 2003. Effects of mini-peptides on the growth performance and the development of small intestines in weaning piglets. Anim. Husbandry Vet. Med., 6: 4-8.

Xu, Z.R., C.H. Hu, M.S. Xia, X.A. Zhan and M.Q. Wang, 2003. Effects of dietary fructooligosaccharide on digestive enzyme activities, intestinal microflora and morphology of male broilers. Poult. Sci., 82: $1030-1036$.

Yen, J.T., A.H. Jensen and J. Simon, 1977. Effect of dietary raw soybean and soybean trypsin inhibitor on trypsin and chymotrypsin activities in the pancreas and in small intestinal juice of growing swine. J. Nutr., 107: 156-165.

Zamora, R.G. and T.L. Veum, 1979. Whole soybeans fermented with Aspergillus oryzae and Rhizopus oliigosporus for growing pigs. J. Anim. Sci., 48: 63-68. 